\title{
Adopting acquisition formula to accommodate the learning needs of the distance learners at OUSL
}

Amarasekara, Ramani ${ }^{1}$

\begin{abstract}
This paper discusses about the possibility of incorporating the component of student learning needs (SLN), to the basic Acquisition Formula designed for the Open University of Sri Lanka. The Acquisition Formula was adopted for the distribution of funds allocated to acquire learning materials, among faculties of a university. The learning component indicates mainly the student requests. Although the formulae developed have been with special reference to the OUSL, they can be adopted to any other university library with minor modifications.
\end{abstract}

Keywords: Student learning needs, Acquisition formula, Distance learners, Budget Allocation

\section{Introduction}

The Academic Library always serves as a scholarly communication platform for teachers, learners and researchers of a university. Though the society transforms into a knowledge society in galloping speed, importance of learning materials in an Academic Library has still not gone into the limelight of the learning scenario. Instead, the learning materials physically form the main focus of an University Library collection. These may range through, printed, electronic, audio-visual, and multimedia to the digital resources. However, the learning materials in a library carry a value in monetary terms. Usually in a University, general library budget is divided among faculties and the library, and the faculties, among departments.

Open University of Sri Lanka, unlike the rest of the conventional universities in Sri Lanka has a student population that is scattered throughout the island. In the OUSL academic setup, face-to-face teaching which the prime teaching method in the conventional

\footnotetext{
${ }^{1}$ Senior Assistant Librarian, Open University of Sri Lanka, Email: ramani.ousl@gmail.com
} 
Journal of the University Librarians Association, Sri Lanka, Vol. 16, Issue 1, January 2012 universities is has been replaced by the provision of course materials prepared by the course development teams of OUSL. Apart from the course materials OUSL students also depend on additional reference materials like textbooks, AV materials and research articles published in subject specific periodicals \& e-journals subscribed by the library and recommended extracts from prose and poems, legal cases etc.

OUSL currently has 5 Regional Centres in the cities of Kandy, Matara, Jaffna, Anuradhapura and Baticaloa, almost covering the Central Province, Southern Province, Northern Province, North-Central Province and the Eastern Province of the island. Libraries in the regional centres have fairly large collections (eg.: KRC has 9461 and MRC has 6530) and therefore attracted a comparable student population.

OUSL also has a network of Study Centres around the suburbs of the Regional Centres. Students registered in the Study Centres have much less facilities and have limited number of reading materials in their respective libraries, compared to the students registered at the main campus and the regional centres. Students registered at study centres have to fulfill their learning needs by traveling to the nearest regional centre or to the main campus. Libraries in Study centers are called "Book cupboards" because of the quantity and subject representation of their collections. Hence, the need is felt for the resources to be equally distributed to the rural student as well as to the urban student.

An Acquisition Formula for acquiring reading materials for the Open University of Sri Lanka has been developed (Amarasekara, 2009) adopting the Material Budget Allocation formula designed by the Angelo State University library (Angelo State University Library, 2011 ; Grace Doherty Library, Centre College, 2007; Drake Memorial Library, 2011; Maxwell, 2011; Riley Hickingbotham Library Ouachita Baptist University,1988). The formula designed for the OUSL library considers the variables such as, academic staff positions, student enrolment, weighted year credit hours, monographs published and research papers published by individual academic departments and summed up to make the Base formula for the university as a whole. 
The objective of this paper is to accommodate the 'student learning needs'(SLN), of the wide-spread student population of the Open University of Sri Lanka (OUSL) which is the prime distance learning institution of Sri Lanka. Distance learning institutions normally adopts Resource-Base Learning (RBL) by their nature.

\section{Acquisition Formulae Developed for OUSL}

An acquisition formula for distribution of funds among various faculties and departments of a university in acquiring library resources has been developed by the author and is tested in the OUSL library system.

The formula was developed with special reference to OUSL and a brief description of the above mentioned formula is included here as an introduction.

\section{Formula 1 for Faculty Allocation}

Formula 1 is for the distribution of total sum of funds (F) received by the Main Library among different faculties of the university. Let $Q_{f}$ denotes the fraction of the material budget to a particular faculty and is computed as the sum of a base component (B) and an Internal component (I) which depends on the student enrolment in the faculty and academic staff positions in the faculty.

$$
\mathrm{Q}_{\mathrm{f}}=\mathrm{B}+\mathrm{I}
$$

\section{Base Component (B)}

Preliminary division of total funds between the Base component(B) and Internal component $(I)$ is in the ratio of $4: 1$ respectively to suit the OUSL requirements.

Base amount (B) consists of $80 \%$ of the total sum of funds received annually divided among different faculties and the library. 
Journal of the University Librarians Association, Sri Lanka, Vol. 16, Issue 1, January 2012

The base amount is divided among Education, Humanities \& Social Sciences(HSS), Natural Sciences \& Engineering Technology faculties and the Library in the ratio of 4:4:2:2:1 respectively.

By defining ratio factor as $\mathrm{R}_{\mathrm{f}}$, base allocation for each faculty can be computed as;

$$
\mathrm{B}=\frac{\mathbf{R}_{\mathbf{f}}}{\sum_{\text {All } \mathbf{R}_{\mathbf{f}} \mathbf{R}_{\mathbf{f}}}}(\mathbf{0 . 8 )}
$$

Library is considered as another faculty with a ratio factor $R_{f}=1$. Here Natural science \& Engineering technology faculties have $R_{f}$ factor as 2 and Education and HSS faculties have $\mathrm{R}_{\mathrm{f}}$ factor as 4 .

\section{Internal Component (I)}

Internal component is computed from previous years data on the number of academic positions (AP) and total student enrolment(SE) of each faulty.

$20 \%$ of the total allocation is equally distributed on the basis of these internal faculty factors as given below:

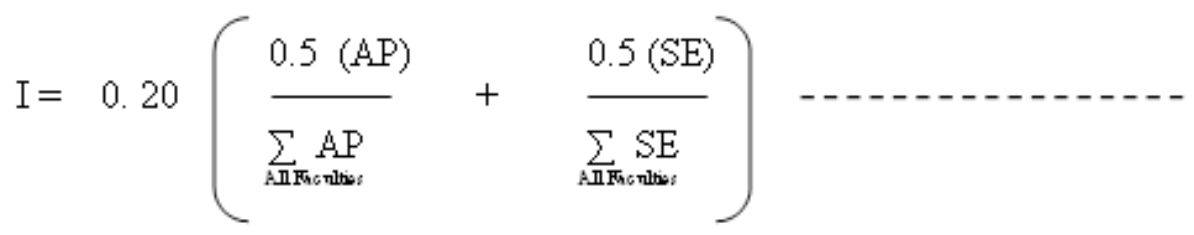

Therefore, by using equations (1) \& (2) the fraction of the material budget to a faculty $\left(Q_{f}\right)$ can be obtained by the formula given below: 


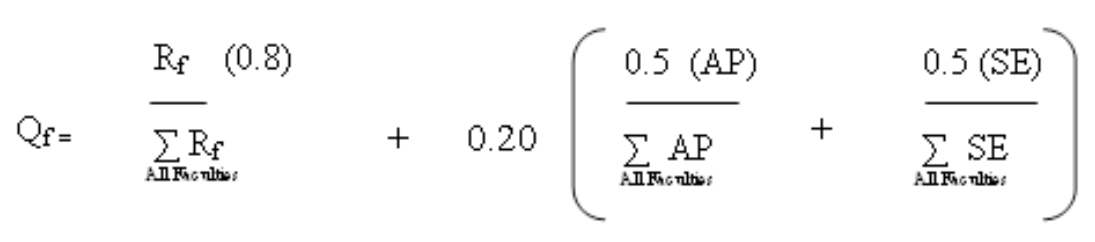

\section{Formula 2 for Departmental Allocation}

Formula 2 is for the distribution of faculty allocation among different departments in the faculty. Let $Q_{d}$ denote the fraction of the material budget to a particular department and is computed as the sum of a base component(B) and an Internal component(I) which depends on the student enrolments number of academic staff positions and the academic workload handled by a particular department. In addition there is an External component (E) which measures research the and publication output of the department.

$$
\mathrm{Q}_{\mathrm{d}}=\mathrm{B}+\mathrm{I}+\mathrm{E}
$$

Preliminary division of total funds between Base component, Internal component and External component is in the ratio of 5:4:1 respectively to suit the OUSL requirements.

\section{Base Component (B)}

$50 \%$ of the distributed funds divided equally among all departments in a faculty.

Therefore,

Base allocation of each department $\quad(B)=\frac{0.5}{\mathrm{ND}}$

ND denotes the number of departments in the faculty. 
Journal of the University Librarians Association, Sri Lanka, Vol. 16, Issue 1, January 2012

\section{Internal Component (I)}

Internal component is computed from prior years data on the number of academic staff members(AS), total number of student enrolment(SE) in a particular department and weighted year credit hour production (WYCH) from the previous year.

$40 \%$ of the total allocation for the faculty is distributed on the basis of these internal factors in the ratio of 1:1:3 and the Internal component can be written as:

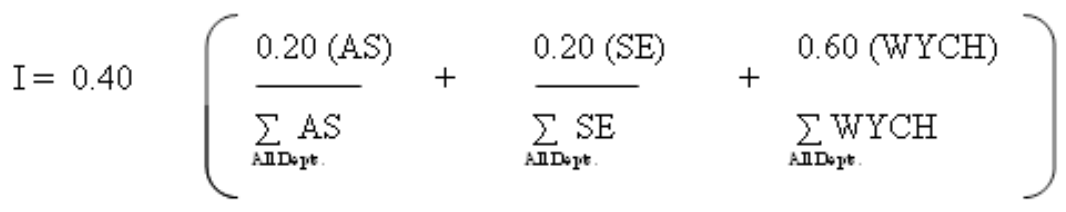

\section{External component (E)}

The remaining $10 \%$ of funds are allocated on the basis number of monographs published (MP) and the number of research papers published (RP) by an academic department in the previous year and divided in the ratio of 3:2 respectively.

Accordingly, the External component can be computed as :

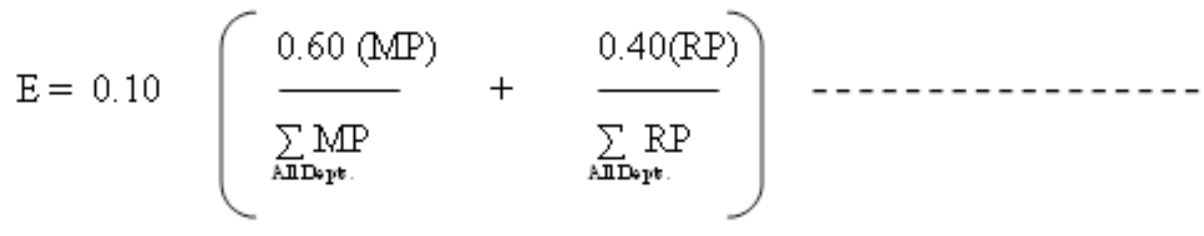

The final formula for the fraction of material budget for the department can be obtained by using equations 4,5 and 6 and is given below:

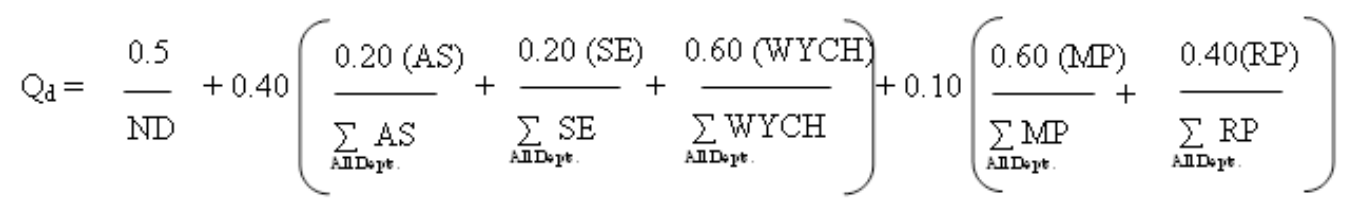


Journal of the University Librarians Association, Sri Lanka, Vol. 16, Issue 1, January 2012

\section{Incorporating learning needs (SLN) of students}

Considering the fact that less weight is given to the learning material needs of students registered at regional and study centres when acquiring materials to the OUSL libraries, the above stated acquisition formula 1 for faculty allocation, has been modified by introducing an additional variable to the formula, to accommodate the student requests.

For the purpose, formula 1 developed previously $(Q=B+1)$, has been modified to include an external component $(E)$, considering the fact that a substantial amount of funds were spent annually to accommodate student requests. The modified new formula is:

$$
Q_{\mathbf{f}}=B_{\mathbf{f}}+I_{\mathbf{f}}+E_{\mathbf{f}}
$$

Modified formula is for the distribution of total sum of funds received by the main library among different faculties of the university. $Q_{f}$ denotes the fraction of the material budget to a particular faculty and is computed as the sum of a base amount $\left(B_{f}\right)$, Internal component $\left(\mathrm{I}_{\mathrm{f}}\right)$ which depends on the student enrolment in the faculty and academic staff positions in the faculty and External component $\left(E_{f}\right)$ computed based on student requests for library materials.

Preliminary division of total funds to Base component, Internal component and External component is in the ratio of 15:4:1 respectively to suit OUSL requirements.

\section{Base Component (Bf)}

Base amount $\left(\mathrm{B}_{\mathrm{f}}\right)$ consists of $75 \%$ of the total sum of funds received annually divided among different faculties and the library. As Engineering technology \& Natural science faculties receive separate additional funds directly from the University for their

Laboratory Developments, the base amount allocation is in the ratio as given below. The fact that the faculties of Education and Humanities \& Social Sciences (HSS) depend heavily on library materials is also taken into consideration and given a higher value for the ratio factor. 
The base amount is divided among Education, Humanities \& Social Sciences, Natural Sciences and Engineering Technology faculties and the library in the ratio of 4:4:2:2:1 respectively.

By defining ratio factor as $\mathrm{R}_{\mathrm{f}}$, base allocation for each faculty can be computed as;

$$
\mathbf{B}_{\mathbf{f}}=\quad \frac{\mathbf{R}_{\mathbf{f}}}{\sum_{\text {Allsankios }} \mathbf{R}_{\mathbf{f}}}(\mathbf{0 . 7 5 )}
$$

Library is considered as another faculty with a ratio factor $R_{f}=1$. Here both Natural Science \& Engineering Technology faculties have $R_{f}$ factor as 2 and both Education and HSS faculties have $R_{f}$ factor as 4 .

\section{Internal Component $\left(I_{f}\right)$}

Internal component is computed from previous years data on the number of academic positions (AP) and total student enrolment(SE) of each faulty.

$20 \%$ of the total allocation is distributed on the basis of these internal faculty factors as given below;

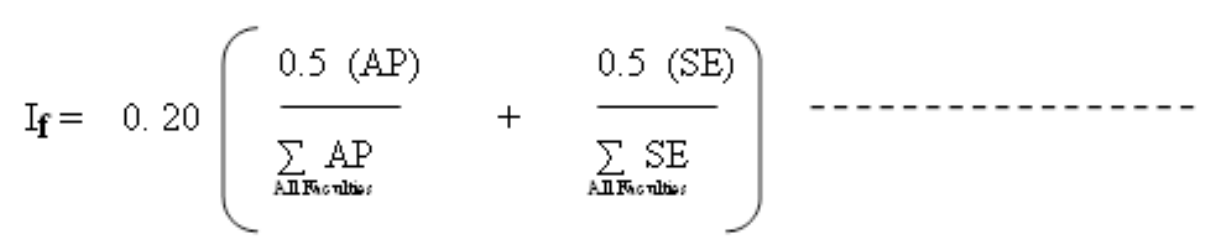

\section{External Component $\left(E_{f}\right)$}

Estimated amount needed to meet the student requests of library materials is considered here as a measure of learning needs of distance learners. This amount is computed faculty wise and included in the formula as SR. The factor SR for a faculty is calculated after considering all requests received within the previous year. $5 \%$ of the total allocation distributed among the faculties on the basis of student requests and are computed as External factor $\mathrm{E}_{\mathrm{f}}$ 
Journal of the University Librarians Association, Sri Lanka, Vol. 16, Issue 1, January 2012

Where,

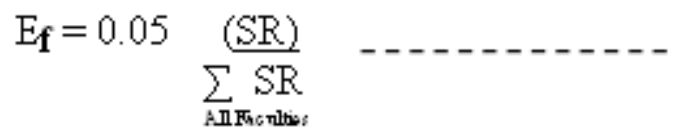

By combining equations 9, 10 and 11 we can obtain the following expression for the faculty allocation as a fraction of total allocation.

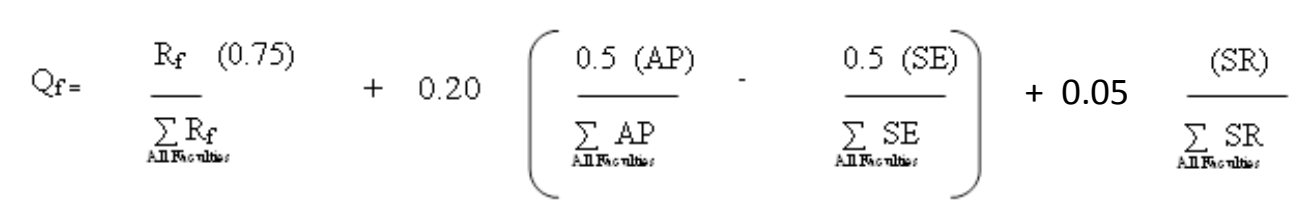

Acquisition formula $\left(Q_{d}\right)$ for the individual departments will remain the same as given in formula (7).

\section{Example for Using the Modified Formula to Compute the Faculty Allocation}

An application of newly developed formula to obtain different faculty allocations when the total funds to be distributed had been 8.0 million rupees is given below. The three components, $B_{f}, I_{f}$ and $E_{f}$ were calculated separately and added together to obtain fraction of material budget for each faculty.

\section{A.)Calculation of the Base Component of Different Faculties}

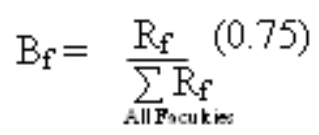


Journal of the University Librarians Association, Sri Lanka, Vol. 16, Issue 1, January 2012

Table 1: Calculation of the Base Component of different faculties

\begin{tabular}{l|lcc}
\hline Faculty & $R_{f}$ & $\sum R_{f}$ & $B_{f}=\frac{R_{f}(0.75)}{\sum \sum_{\text {All } \sum_{\text {suk }} R_{f}}}$ \\
& & & $0.75 \times 4 / 13=0.2308$ \\
\hline Education & 4 & 13 & $0.75 \times 2 / 13=0.1154$ \\
Engineering Technology & 2 & 13 & $0.75 \times 4 / 13=0.2308$ \\
Humanities\&Social Sciences & 4 & 13 & $0.75 \times 2 / 13=0.1154$ \\
Natural Sciences & 2 & 13 & $0.75 \times 1 / 13=0.0577$ \\
Library & 1 & 13 & \\
\hline
\end{tabular}

\section{B.)Calculation of the Internal Component of Different Faculties}

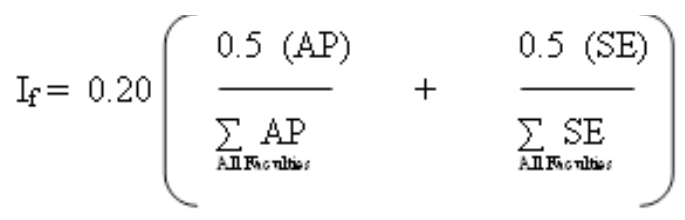

Table 2: Calculation of the Internal Component of different faculties

\begin{tabular}{|c|c|c|c|c|c|c|c|}
\hline Faculty & $A P$ & $S E$ & $\Sigma A P$ & $\Sigma S E$ & $\frac{0.5(A P)}{\sum A P}$ & $\frac{0.5(S E)}{\Sigma S E}$ & $I_{f}$ \\
\hline Education & 33 & 4874 & 270 & 18243 & 0.0611 & 0.1336 & 0.03894 \\
\hline $\begin{array}{l}\text { Engineering } \\
\text { Technology }\end{array}$ & 76 & 1522 & 270 & 18243 & 0.1407 & 0.0417 & 0.03648 \\
\hline $\begin{array}{l}\text { Humanities \& } \\
\text { Social Sciences }\end{array}$ & 66 & 5722 & 270 & 18243 & 0.1222 & 0.1568 & 0.0558 \\
\hline Natural Sciences & 86 & 6125 & 270 & 18243 & 0.1593 & 0.1679 & 0.06544 \\
\hline Library & 09 & 00 & 270 & 18243 & 0.0167 & 00 & 0.00334 \\
\hline
\end{tabular}


Journal of the University Librarians Association, Sri Lanka, Vol. 16, Issue 1, January 2012

The student enrolment (SE) and the academic positions (AP) given here are actual figures of relevant faculties in 2010 for the OUSL.

\section{C.)Calculation of the External Component of Different Faculties}

$$
\mathrm{E}_{\mathrm{f}}=(0.05) \frac{\mathrm{SR}}{\sum_{\text {AnI Thontlios }} \mathrm{SR}}
$$

Table 3: Calculation of the External Component of different faculties

\begin{tabular}{l|lll}
\hline Faculty & $S^{*}$ (nupees) & $\sum S R$ (nupees) & $\mathrm{E}_{\mathrm{f}}$ \\
\hline Library & 00 & 50,000 & 00 \\
Natural Sciences & 20,000 & 50,000 & 0.02 \\
Engineering Technology & 20,000 & 50,000 & 0.02 \\
Humanities\& Social Sciences & 5,000 & 50,000 & 0.005 \\
Education & 5,000 & 50,000 & 0.005 \\
\hline
\end{tabular}

* Hypothetical values were assigned for (SR) of each faculty.

\section{Calculation of the Faculty Allocation as a Fraction of Total Allocation}

Table 4: Calculation of the faculty allocation as a fraction of total allocation

\begin{tabular}{l|llll}
\hline Faculty & $B_{f}$ & $I_{f}$ & $E_{f}$ & $\mathrm{Q}_{f}=\mathrm{B}_{f}+l_{f}+\mathrm{E}_{f}$ \\
\hline Education & 0.2308 & 0.03894 & 0.005 & 0.27474 \\
Engineering Technology & 0.1154 & 0.03648 & 0.02 & 0.17188 \\
$\begin{array}{l}\text { Humanities \& Social } \\
\text { Sciences }\end{array}$ & 0.2308 & 0.0558 & 0.005 & 0.2916 \\
Natural Sciences & 0.1154 & 0.06544 & 0.02 & 0.20084 \\
Library & 0.0577 & 0.00334 & 00 & 0.06104 \\
\hline
\end{tabular}


Journal of the University Librarians Association, Sri Lanka, Vol. 16, Issue 1, January 2012

Final Faculty Allocation if the Total Available Library Funds is Taken as 8 Million Rupees

Table 5: Final faculty allocation

\begin{tabular}{l|ll}
\hline Faculty & $Q_{f}$ & $Q_{f} \times 8.0$ million Rupees \\
\hline Education & 0.27474 & $0.27474 \times 8=2.19792$ \\
Engineering Technology & 0.17188 & $0.17188 \times 8=1.37504$ \\
Humanities \& Social & 0.2916 & $0.2916 \times 8=2.3328$ \\
Sciences & & \\
Natural Sciences & 0.20084 & $0.20084 \times 8=1.60726$ \\
Library & 0.06104 & $0.06104 \times 8=0.48832$ \\
\hline Total & & $(8000340$ rupees) approx. 8.0 million Rs. \\
\hline
\end{tabular}

\section{Concluding Remarks}

The paper discusses the acquisition formula that has been adopted for the budget allocation for acquiring learning materials to the Open University of Sri Lanka library system. The validity of the formula is, that it can be adopted to any type of library, adding or dropping the variables relevant to different library funding systems. Since the student learning needs (SLN) became the focus of the student-centered learning paradigms, the acquisition formula however, is not highly valid if the SLN component is neglected. Therefore the basic acquisition formula is incorporated with the SLN component and reformulated in this paper. In addition, an actual funding scenario is also calculated and presented for the proper understanding of possible usage of modified acquisition formula. 
Journal of the University Librarians Association, Sri Lanka, Vol. 16, Issue 1, January 2012

\section{Note:}

The basic formula and its description in full detail is being accepted for the journal "Information Age", volume 6(1) Jan-March, 2012.

Publisher: Dr. PSG Kumar Library Foundation, Nagpur, (India)

\section{References:}

Amarasekara, R.(2009). Manual of procedure: Acquisitions Division, Library Open University of Sri Lanka, Nawala.10p.(unpublished)

Angelo State University Library: Collection Development Policy. (2011). Retrieved from www.angelo.edu/services/library/documents/ppm8.docx.

Grace Doherty Library, Centre College. (2007). Acquisitions Policy Retrieved from http://www.centre.edu/web/library/about/policies.html.

Drake Memorial Library. (2011). Allocation Formula Factors Retrieved from http://www.brockport. edu/library/acquisitions/formula . IBA Libraries: Institute of Business Administration (Karachi): Acquisition System.

Maxwell, J. (2011). Ohio University Libraries Acquisitions formula. Retrieved from http://www.library.ohiou.edu/info/colldev/formula.html.

Riley Hickingbotham Library Ouachita Baptist University. (1988). Acquisitions Policy. ; Retrieved from http://library.obu.edu/AcquisitionsPolicy.pdf. 